\title{
Exclusive Breast Feeding Status and its Determinant among HIV Positive Women in West Showa Zone Oromia Region Ethiopia
}

\section{Bayissa ZB*}

Ambo University, College of Medicine and Health sciences, Ambo, Ethiopia

\begin{abstract}
Introduction: During the first six months of their life replacement feeding is recommended for infants born from HIV positive women under the condition of acceptable, feasible, affordable, sustainable and safe. Where this is not achievable, exclusive breastfeeding (EBF) is suggested during the first six months of life.

Objective: To assess the EBF practice of HIV positive women and its determinants with in a selected health facilities of West showa zone Oromia region.

Methods: Institutional based cross-sectional study was carried out among HIV-positive women attending PMTCT service using structured questioners. Consecutive sampling technique was applied in order to interview women. Data was analyzed using SPSS version 16.0 and multiple variable logistic regressions were done to identify risk factors of Exclusive breast feeding

Result: The proportion of exclusive breast feeding was $23.98 \%$. Majority $(79.34 \%)$ of the study subjects knew that HIV can transmit from mother to child during breast feeding. Mothers who had secondary educational status were three times more likely to give exclusive breast feeding than those who had no formal education (OR, $3.0495 \% \mathrm{Cl}=2.72$, 6.52). Mothers with household income earned 500-1000 birr were 2 times more likely to practice EBF than who earned 2000 birr (OR, $2.1195 \% \mathrm{Cl}=1.93,3.50)$. Compared to government employee women those who have self employee were 3.5 times more likely to practice EBF (OR, 3.51 95\% Cl=1.65-6.37). Mothers who delivered by $\mathrm{C} / \mathrm{S}$ were 2.01 times more likely to practice EBF than those delivered by SVD (OR, 2.0195\% Cl=1.07-4.38).
\end{abstract}

Conclusion: The study revealed important findings which affect the practice of exclusive breast feeding of HIV positive mothers. All concerned bodies involvement is necessarily on infant feeding counseling to bring behavioral change in within communities for the better life of newborns.

\section{Keywords: Breast feeding; HIV positive women; HIV}

\section{Introduction}

Exclusive breastfeeding (EBF) for infants within the first six months of life helps to achieve best development, growth and health. According to WHO recommendation infants begin receiving complementary foods at the age of six months in addition to breast milk [1]. Promotion of breastfeeding has played an important role in protecting infants and young children, since breastfeeding provides optimal nutrition, protects against common childhood infections, reduces mortality significantly and has child-spacing effects [2,3]. Having this recommendation there is a debate about the advantages of exclusive breast feeding for life saving benefits and the risk of HIV transmission through breastfeeding to infants after delivery. So these two ideas complicate infant feedings practice of women affected by HIV/AIDS. The rising of HIV/AIDS epidemic and the detection that HIV can transmit from positive mothers to their babies through breast milk create a terrible public health dilemma within countries of high incidences of HIV. In response to this problem in 2003, a guideline was developed by UNICEF, WHO, UNAIDS and UNFPA in the circumstance of infant feeding of women whose HIV status is unknown and HIV positive women [4]. The suggested option for HIV positive women is not giving $\mathrm{BF}$ when replacement feeding (RF) is Acceptable, Feasible, Affordable, Sustainable and Safe (AFASS). However, if the criteria of AFASS cannot be met, the second choice is to give exclusively BF and avoid mixed feedings. Other feeding options recommended when the AFASS criteria are not possible are to use heat treated expressed breast milk or wet nursing of the newborn by HIV negative [5].

By 2011, there were around 330,000 children newly infected with Human Immunodeficiency Virus (HIV); and majority of the infections were occurring in sub-Saharan African countries. Ethiopia is one among ten countries in the world with the highest load of HIV infections among children in which mother-to-child transmission (MTCT) occurs in a third of infants born to HIV-infected mothers. In young children the most significant source of HIV infection is MTCT. Without specific interventions HIV can be transmitted during pregnancy, delivery, or through breast milk. In 2012, the prevalence of HIV at antenatal care clinics was $2.4 \%$ and MTCT ranges from $17 \%$ to $30 \%$ including breastfeeding, amounting to an estimated 13,000 new HIV infections among children [6,7].

Compared to exclusively breast-fed infants in mixed fed infants the vertical transmission of HIV from mother to child is higher. It is predictable that with Exclusive Breastfeeding (EBF) practice, 13\% to $15 \%$ deaths of children less than 5 years of age could be prevented in low and middle-income countries. The recommendation of WHO about EBF is for both HIV exposed and none exposed infants for the first six months of life, however still the rates of EBF remain low all over the world [8].

${ }^{*}$ Corresponding author: Zenebu Begna Bayissa, Department of health officer, Ambo University, College of Medicine and Health sciences, Ambo 19, Ethiopia, Tel: +919871298827; E-mail: zeni.begna@gmail.com

Received November 15, 2016; Accepted December 13, 2016; Published December 20, 2016

Citation: Bayissa ZB (2016) Exclusive Breast Feeding Status and its Determinant among HIV Positive Women in West Showa Zone Oromia Region Ethiopia. J AIDS Clin Res 8: 646. doi:10.4172/2155-6113.1000646

Copyright: (c) 2016 Bayissa ZB. This is an open-access article distributed unde the terms of the Creative Commons Attribution License, which permits unrestricted use, distribution, and reproduction in any medium, provided the original author and source are credited. 
In 2011, adult HIV/AIDS prevalence in Ethiopia was estimated at $1.5 \%$ with $1 \%$ among males and $1.9 \%$ among females. This data indicates adult prevalence was almost twice as high among females compared to males. Over $8 \%$ of pregnant women in Ethiopia were estimated to be living with HIV in 2007 [9]. There is no study is conducted as far as the researcher knowledge is concerned in this specific area when this study was planned. Thus, this study will add the understanding on the observed gap in this area by identifying factors influencing EBF practice among HIV positive women in west showa zone. The findings of this study are expected to inform all stake holders and decision makers to develop right interventions based on identified problems to encourage exclusive breastfeeding for development of child health.

\section{Methods}

\section{Study area}

A cross-sectional study was conducted in PMTCT clinics of west showa zone in 2014.

\section{Study population, sample size and sampling}

Eligible respondents were; HIV positive mothers who attended PMTCT programme from three hospitals purposely selected from the zone based on the number of women attending ART and PMTCT services, (namely Ambo, Gedo and Gindeberet hospitals) mothers of babies less than 12 months and those attending PMTCT services above six months before the study was interviewed.

Excluding criteria: Those who were sick and unable to give information during the study time.

Sample size determination: The sample size was calculated using formula for single population proportion. The sample size was determined by assuming $50 \%$ the prevalence rate with $95 \%$ confident level, $5 \%$ precision and considering for a non-response rate of $10 \%$. Totally 422 samples was calculated. Consecutive sampling technique was used until the required sample was obtained. A structured and pre-tested questionnaire was used to collect the data and it contains socio-demographic, feeding practices, health status and other relevant information. Data was collected from February to March 2014, by health professional of respective health institutions after obtaining training on how to collect the data. In order to avoid the risk of double interview code number was assigned on the women's follow up card. To keep the quality of data each filled questionnaire was checked for accuracy and completeness of the information by supervisor and the principal investigator.

\section{Data analysis}

Data was analyzed using SPSS version 16.0. In order to check for any inconsistencies, coding error, out of range, and missing values data exploration were made and appropriate corrections. A descriptive analysis was done and infant feeding practices were carried out. Bivariate logistic regression model was used to assess associations of each independent variable with the outcome variable at $p$ value of 0.25 . Finally, all variables which had shown significant association at $P$ value less than 0.25 in the bivariate model were included in the final multivariate logistic regression model and their adjusted odds ratios were calculated. All variables which had shown significant association at $p<0.05$ in the final model were considered as independent determinant factors of exclusive breast feeding practice of HIV positive mothers.

\section{Ethical issues}

The ethical review team of the Ambo University College of medicine and health sciences approved the study for its ethical and scientific value. Official consent letter was given for the selected health facilities to get permission to go through the data collection process. Finally informed verbal consent was also obtained from the study subjects and the right of mothers to withdraw from the study at any time was informed and respected.

\section{Results}

Totally 392 HIV-positive mothers were included in the study as actual participants. The response rate of the study was about $93 \%$.

The highest proportion of mothers $158(40.31 \%)$ was in age group $25-30$ years and followed by $78(19.9 \%) 20-24$ years. The mean maternal age was $27.3+3.42$ years $(S . D=3.42)$.

The findings showed that the highest proportion of respondents were from orthodox religion groups $220(56.12 \%)$ followed by protestant 123 (31.38\%), Muslim 40 (10.2\%) and catholic 9 (2.3\%).

The study revealed that more than half $258(65.82 \%)$ of the respondents were married at the time of interview while $78(19.9 \%)$ were divorced. Single mothers were 51 (13.01\%).

In this study majority 170 (43.37\%) of respondents attained secondary level of education and followed by 133 (33.93) primary level education while 68 (17.35) had no formal education and 21 (5.36) had attained college/university. The Table 1 describes the sociodemographic characteristics of respondents.

\begin{tabular}{|c|c|c|}
\hline Variables & Number & Percent \\
\hline \multicolumn{3}{|l|}{ Age } \\
\hline $15-20$ & 19 & 4.85 \\
\hline $20-25$ & 78 & 19.90 \\
\hline $25-30$ & 158 & 40.31 \\
\hline $30-35$ & 26 & 6.63 \\
\hline $35-40$ & 42 & 10.71 \\
\hline $40-45$ & 49 & 12.50 \\
\hline $45-50$ & 20 & 5.10 \\
\hline \multicolumn{3}{|l|}{ Religion } \\
\hline Orthodox & 220 & 56.12 \\
\hline Protestant & 123 & 31.38 \\
\hline Muslim & 40 & 10.20 \\
\hline Catholic & 9 & 2.30 \\
\hline \multicolumn{3}{|l|}{ Ethnicity } \\
\hline Oromo & 312 & 79.59 \\
\hline Amhara & 59 & 15.05 \\
\hline Others & 21 & 5.35 \\
\hline \multicolumn{3}{|l|}{ Marital status } \\
\hline Married & 258 & 65.82 \\
\hline Divorce & 78 & 19.90 \\
\hline Single & 51 & 13.01 \\
\hline Widowed & 5 & 1.28 \\
\hline \multicolumn{3}{|l|}{ Educational status } \\
\hline No formal education & 68 & 17.35 \\
\hline Primary education & 133 & 33.93 \\
\hline Secondary education & 170 & 43.37 \\
\hline College/University & 21 & 5.36 \\
\hline \multicolumn{3}{|l|}{ Occupation } \\
\hline House wife & 204 & 52.04 \\
\hline Government employee & 115 & 29.33 \\
\hline Merchant & 57 & 14.54 \\
\hline Others & 16 & 4.08 \\
\hline
\end{tabular}

Table 1: Socio-demographic characteristics of mothers in west showa zone Oromia region 2014. 


\section{Level of maternal knowledge on MTCT of HIV}

The respondents' knowledge on HIV, timing of transmission from mother to the child and prevention of transmission were analyzed. Accordingly all of the respondents knew that HIV could be transmitted from mother to child during pregnancy and delivery, $311(79.34 \%)$ during breast feeding. Majority of the respondents knew about prevention of mother to child transmission during Pregnancy 286 (72.96\%), during delivery 273 (69.64\%) and breastfeeding 298 (76.02\%).

\section{Infant feeding practices}

This study examines infant feeding practices among HIV positive mothers study subjects. The common infant feeding practices mentioned by participants were breast feeding, replacement feeding and mixed feeding. Majority of them applied mixed feeding practice 256 (65.31\%). The rest $94(23.98 \%)$ and $42(10.71 \%)$ were practice exclusive breast feeding and Exclusive replacement feeding respectively. The following Figure 1 showed us the proportion of feeding practice among women of the study area.

\section{Factors associated with exclusive breast feeding}

In order to see the associated factors of exclusive breast feeding multiple logistic regressions was done. Accordingly education of mothers, income, maternal employment, ANC visit, and mode of delivery had shown significant association with $\mathrm{EBF}$ at $\mathrm{p}<0.05$.

Mothers who had secondary educational status were three times more likely to give exclusive breast feeding than those who had no formal education (OR, $3.0495 \% \mathrm{CI}=2.72,6.52$ ). Mothers with household income earned 500-1000 birr were 2 times more likely to practice EBF than who earned 2000 birr (OR, $2.1195 \% \mathrm{CI}=1.93$, 3.50). Compared to government employee women those who have self employee were 3.5 times more likely to practice EBF (OR, $3.5195 \%$ $\mathrm{CI}=1.65-6.37)$. Mothers who delivered by $\mathrm{C} / \mathrm{S}$ were 2.01 times more likely to practice EBF than the referent groups (OR, 2.01 95\% CI=1.074.38). The following Table 2 summarizes the determinants of EBF among HIV positive women of the study area.

\begin{tabular}{|c|c|c|c|}
\hline Variables & EBF & COR $(95 \% \mathrm{CI})$ & AOR (95\% Cl) \\
\hline \multicolumn{4}{|l|}{ Educational status } \\
\hline No education & 8 & 1 & 1 \\
\hline Primary & 15 & $1.70(0.54-3.33)$ & $0.84(0.50,1.36)$ \\
\hline Secondary & 54 & $4.11(2.02-7.51)$ & $3.04(2.72,6.52)$ \\
\hline College/University & 17 & $1.82(0.81-4.10)$ & $0.34(0.10,3.41)$ \\
\hline \multicolumn{4}{|l|}{ Income } \\
\hline $500-1000$ & 26 & $2.52(1.52,4.42)$ & $2.11(1.93,3.50)$ \\
\hline $1001-1500$ & 48 & $0.75(0.23-1.19)$ & $1.11(0.42-4.73)$ \\
\hline $1501-2000$ & 11 & $1.81(0.21,2.75)$ & $2.17(0.40,3.38)$ \\
\hline$>2000$ & 9 & 1 & 1 \\
\hline \multicolumn{4}{|l|}{ Maternal occupation } \\
\hline Government employee & 14 & 1 & 1 \\
\hline Self-employee & 80 & $2.11(1.03-4.29)$ & $3.51(1.65-6.37)$ \\
\hline \multicolumn{4}{|l|}{ ANC visit } \\
\hline One times & 5 & 1 & 1 \\
\hline Two times & 16 & $0.42(0.29,2.54)$ & $3.67(0.12,4.81)$ \\
\hline Three times & 46 & $1.95(1.41,3.75)$ & $2.15(1.24,5.35)$ \\
\hline Four times & 27 & $2.63(1.01,4.20)$ & $3.15(1.91,6.31)$ \\
\hline \multicolumn{4}{|l|}{ Mode of delivery } \\
\hline SVD & 51 & 1 & 1 \\
\hline CS & 43 & $2.60(1.25-5.39)$ & $2.01(1.07-4.38)$ \\
\hline
\end{tabular}

Table 2: Variable which had shown significant association in multiple variable regressions.

\section{Feeding Practice}

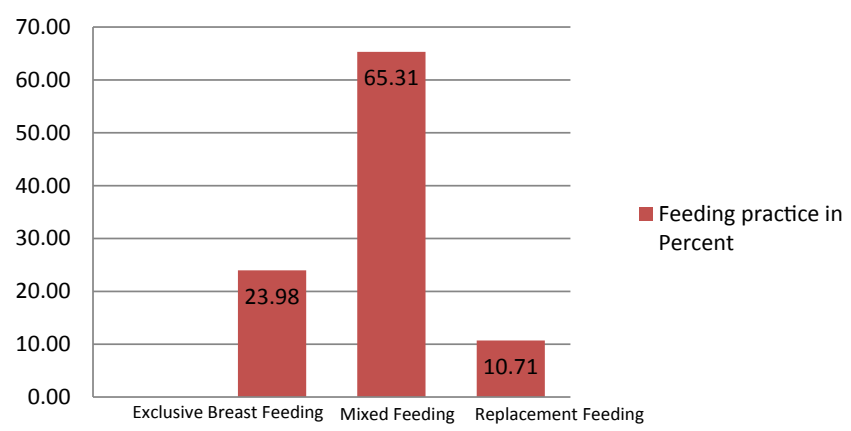

Figure 1. Feeding practice of HIV positive women in west showa zone Oromia region 2014.

\section{Discussion}

The Global Strategy for Infant and Young Child Feeding without any doubt sets out that, as a public health suggestion, exclusive breastfeeding is advisable for the first six months of infant's life to achieve development, optimal growth, and health. Then after, infants should take nutritionally adequate and safe complementary food and breastfeeding continues until two years of age and beyond. However, feeding of children being born from HIV-positive woman has unusually difficult circumstances. For those kinds of children formula or replacement feeding (RF) for infants of HIV positive women is the recommended choice to avoid the risk of HIV transmission from mother to child during breastfeeding $[1,4,10]$.

In this study, the proportion of HIV mothers' who had practiced EBF for the first 6 months their baby's life is low (23.98\%) compared to other study. This finding is lower than the study conducted in West Oromia $72 \%$, in Nigeria $68.3 \%$, in India $44 \%$ and have some similarity with study conducted in Uganda $24 \%$ whereas nearly close to study done in Addis Ababa $30.6 \%$ of the study members had practiced EBF [4,11-14]. The observed comparative difference could be due to the fear of the risk from vertical transmission of HIV/AIDS that is mother to child.

The other essential finding of the present study was EBF practice was significantly associated with maternal education. Mothers who had secondary educational status were three times more likely to give exclusive breast feeding than those who had no formal education. This result is in line with study done at Addis Ababa which showed as when the education of mother increases the probability of practicing EBF was also increased. Additionally this result also similarly agrees with mother of non HIV positive women but conducted to look the factors of EBF.

The practice of exclusive breast feeding among HIV positive mother of this study area was also associated with their income level. As it is known income plays role for the buying capacity of a person. Those low income categories had practice of EBF which is comparable to the study conducted in Nigeria and Kenya [12,15]. This study identified that employment states as significant variable for EBF of women living with HIV/AIDS. Self-employed women practice EBF than that of government employee which had agreement with other finding of the study conducted in Ethiopia [16]. This could be due to the fact that government employee should serve at least eight hours in the office and cannot have the opportunity to stay with their baby and feeds enough duration. 
Citation: Bayissa ZB (2016) Exclusive Breast Feeding Status and its Determinant among HIV Positive Women in West Showa Zone Oromia Region Ethiopia. J AIDS Clin Res 8: 646. doi:10.4172/2155-6113.1000646

The other important finding of the study was ANC visit. When the number of visit increases the probability of women practicing exclusive breast feeding increases. In the current study women who had four ANC visit practice three times more than that had one ANC visit. This showed as when women receive ANC visit it has an advantage on choice of infant feeding options suggested for HIV positive mothers chose exclusive breastfeeding as an option to feeding their children and creates impact up on choice of feeding practice [12].

Mode of delivery was one variable which showed association with feeding practice of women. Compared to spontaneous vertex delivery (SVD) those delivered by $\mathrm{C} / \mathrm{S}$ were more likely to practice EBF. The finding of this study disagree with the study conducted at Addis Ababa in which mothers who had delivered by $\mathrm{C} / \mathrm{S}$ were more likely to practice replacement feeding than EBF [4].

\section{Conclusion}

Infant feeding is important in early life and key element to child continued existence and development. This is very difficult in context of HIV/AIDS because of transmission from mother to child. The prevalence of EBF in the study area was $23.98 \%$. This low prevalence of EBF among HIV/AIDS positive women could be due to the risk of transmission. Majority (79.34\%) of the study subjects knew that HIV can transmit from mother to child during breast feeding. In this study variable which had shown significant association with exclusive breast feeding practice of HIV positive women were maternal education, income status, and maternal employment status, number of ANC visits and mode of delivery. In general finding of the study would inform us to develop an intervention mechanism by all stake holders and concerned bodies on identified risk factors.

\section{Acknowledgement}

The author would like to extend gratitude and appreciation to Ambo University College of Medicine and Health Sciences.

\section{References}

1. World Health Organization (2009) Infant and young child feeding (IYCF) model chapter for textbooks for medical students and allied health professionals. WHO, Switzerland.
2. Gartner LM, Morton J, Lawrence RA, Naylor AJ, O'Hare D, et al. (2005) Breastfeeding and the use of human milk. Pediatrics 115: 496-506.

3. Horta BL, Bahl R, Martines JC, Victora CG; WHO (2007) Evidence on the long term effects of breastfeeding. Systematic Reviews and Meta Analyses. WHO, Geneva

4. Maru Y, Haidar J (2009) Infant feeding practice of HIV positive mothers and its determinants in selected health institutions of Addis Ababa, Ethiopia. Ethioipian Journal of Health Development 23.

5. UNAIDS (2004) Infant feeding options in the context of HIV, Academy for Educational Development. Linkages, Washington, DC 2004: 3-17.

6. WHO UNAIDS (2015) 2015 Progress Report on the global plan towards the elimination of new HIV infections among children by 2015 and keeping their mothers alive. WHO, UNAIDS, Geneva, Switzerland.

7. FDRE-HAPCO (2012) Country progress report on HIVIAIDS response. Federal Democratic Republic of Ethiopia.

8. Coovadia H, Rollins N, Bland R, Little K, Coutsoudis A, et al. (2007) Mother-tochild transmission of HIV-1 infection during exclusive breastfeeding: The firs six months of life: An interve intervention cohort study. Lancet 369:1107-1116.

9. Ethiopia Demographic and Health Survey 2011 (2012) Central Statistical Agency Addis Ababa, Ethiopia, ICF International Calverton, Maryland, USA.

10. UNICEF, UNAIDS, WHO, UNFP (2003) HIV and infant feeding: A guide for health-care managers and supervisors.

11. Bekere A, Garoma W, Beyene F (2014) Exclusive breastfeeding practices of HIV positive mothers and its determinants in selected health institution of West Oromia, Ethiopia. J Nutr Food Sci 4: 6

12. Adejuyigbe E, Orji E, Onayade A, Makinde N, Anyabolu H (2008) Infant feeding intentions and practices of HIV-positive mothers in south-western Nigeria. $J$ Hum Lact 24: 303-310.

13. Suryavanshi N, Jonnalagadda S, Erande AS, Sastry J, Pisal H, et al. (2003) Infant feeding practices of HIV-positive mothers in India. J Nutr 133: 1326-1331.

14. Fadnes LT, Engebretsen IM, Wamani H, Semiyaga NB, Tylleskär T, et al (2009) Infant feeding among HIV-positive mothers and the general population mothers: Comparison of two cross-sectional surveys in Eastern Uganda. BMC Public Health 9: 124

15. Wapang'ana G (2013) Assessment of factors influencing infant feeding practices among HIV positive mothers in Rongo District, Western Kenya. MPH Thesis School of Public Health. Kenyatta University.

16. Alemayehu T, Haidar J, Habte D (2009) Determinants of exclusive breastfeeding practices in Ethiopia. Ethiop J Health Dev 23: 12-8. 